\title{
Prostate-Specific Membrane Antigen-Based Therapeutics
}

\author{
Naveed H. Akhtar, ${ }^{1}$ Orrin Pail,, ${ }^{1}$ Ankeeta Saran, ${ }^{1}$ Lauren Tyrell, ${ }^{1}$ and Scott T. Tagawa ${ }^{1,2}$ \\ ${ }^{1}$ Division of Hematology and Medical Oncology, Weill Cornell Medical College, 525 E. 68th Street, Box 403, New York, \\ NY 10065, USA \\ ${ }^{2}$ Department of Urology, Weill Cornell Medical College, 525 E. 68th Street, Box 403, New York, NY 10065, USA
}

Correspondence should be addressed to Scott T. Tagawa, stt2007@med.cornell.edu

Received 2 May 2011; Accepted 9 May 2011

Academic Editor: Maximilian Burger

Copyright ( $) 2012$ Naveed H. Akhtar et al. This is an open access article distributed under the Creative Commons Attribution License, which permits unrestricted use, distribution, and reproduction in any medium, provided the original work is properly cited.

\begin{abstract}
Prostate cancer (PC) is the most common noncutaneous malignancy affecting men in the US, leading to significant morbidity and mortality. While significant therapeutic advances have been made, available systemic therapeutic options are lacking. Prostatespecific membrane antigen (PSMA) is a highly-restricted prostate cell-surface antigen that may be targeted. While initial antiPSMA monoclonal antibodies were suboptimal, the development of monoclonal antibodies such as J591 which are highly specific for the external domain of PSMA has allowed targeting of viable, intact prostate cancer cells. Radiolabeled J591 has demonstrated accurate and selective tumor targeting, safety, and efficacy. Ongoing studies using anti-PSMA radioimmunotherapy with ${ }^{177} \mathrm{Lu}-$ J591 seek to improve the therapeutic profile, select optimal candidates with biomarkers, combine with chemotherapy, and prevent or delay the onset of metastatic disease for men with biochemical relapse. Anti-PSMA monoclonal antibody-drug conjugates have also been developed with completed and ongoing early-phase clinical trials. As PSMA is a selective antigen that is highly overexpressed in prostate cancer, anti-PSMA-based immunotherapy has also been studied and utilized in clinical trials.
\end{abstract}

\section{Prostate-Specific Membrane Antigen}

Prostate-specific membrane antigen (PSMA) is the single most well-established, highly specific prostate epithelial cell membrane antigen known [1-6]. The PSMA gene has been cloned, sequenced, and mapped to chromosome $11 \mathrm{p}$ $[2,7]$. Pathology studies indicate that PSMA is expressed by virtually all prostate cancers [7-10]. Moreover, PSMA expression increases progressively in higher-grade cancers, metastatic disease and castration-resistant prostate cancer (CRPC) $[3,4,11,12]$. Although first thought to be entirely prostate-specific [1-3], subsequent studies demonstrated that cells of the small intestine, proximal renal tubules, and salivary glands also express PSMA [5]. Importantly, the expression in normal cells is 100-1000-fold less than in prostate tissue [6], and the site of expression is not typically exposed to circulating intact antibodies [5]. In addition, PSMA is expressed on the neovasculature of the vast majority of solid tumor malignancies, but not on the normal vasculature [13]. In contrast to other well-known prostaterestricted molecules such as prostate-specific antigen (PSA) and prostatic acid phosphatase (PAP) that are secretory proteins, PSMA is an integral cell-surface membrane protein that is not secreted, thereby making PSMA an ideal target for monoclonal antibody $(\mathrm{mAb})$ therapy.

Prostate-specific membrane antigen has been found to have folate hydrolase and neurocarboxypeptidase activity [14]. Although its role in prostate cancer (PC) biology is unknown, the consistent finding of PSMA upregulation correlating with increased aggressiveness of the cancer implies that PSMA has a functional role in PC progression. Inhibition of enzymatic activity in vitro or in xenograft models has not demonstrated significant growth inhibitory effect (N. H. Bander et al., unpublished data). Nevertheless, the expression pattern of PSMA makes it an excellent target for mAb-based targeted therapy of PC.

Prostate-specific membrane antigen was initially validated as an in vivo target for imaging utilizing radiolabeled mAb 7E11 (CYT-356, capromab) [15, 16]. Capromab pendetide imaging was approved to evaluate the extent of disease in patients presenting with Gleason sums greater than 6 and those who experience a rising PSA after prostatectomy. 
Though improvements have been made with single-photon emission computed tomography (SPECT) and SPECT/CT imaging, because of suboptimal sensitivity and specificity of capromab pendetide, this imaging tool has not been widely adopted $[17,18]$. Molecular mapping revealed that 7E11 targets a portion of the PSMA molecule that is within the cell's interior and not exposed on the outer cell surface $[5,19,20]$ and cannot bind to viable cells $[1,20]$. Recognition of these features by Bander and colleagues at Weill Cornell Medical College led to the development of mAbs to the exposed, extracellular domain of PSMA. In theory, the bound mAbs to the PSMA molecule would have the potential to significantly improve in vivo targeting and likely result in enhanced imaging and therapeutic benefit [20-22]. After testing, these antibodies (J591, J415, J533, and E99) did indeed demonstrate high-affinity binding to viable PSMA-expressing LNCaP cells in tissue culture and were rapidly internalized $[20,21]$. Amongst these antibodies, the deimmunized IgG monoclonal antibody known as J591 was the most highly developed antibody clinically [23].

\section{Radioimmunotherapy: Background and Rationale for Prostate Cancer}

Radioimmunotherapy (RIT) is a technique by which a radionuclide is linked to a $\mathrm{mAb}$ or peptide and is typically delivered in a systemic fashion. In clinical practice, mAbs and peptides can be labeled with radionuclides that are usually beta-emitters. This "targeted" form of RT allows radiation delivery to tumors while sparing normal organs. The initially investigated form of RIT utilized radiolabeled antibodies against carcinoembryonic antigen for solid tumors. To date, the most studied form of RIT targets the CD20 antigen $\left({ }^{131} \mathrm{I}\right.$ tositumomab or ${ }^{90} \mathrm{Y}$ ibritumomab tiuxetan) in nonHodgkin's lymphoma, demonstrating safety and efficacy in phase I-III trials, which led to FDA approval. RIT for solidtumor malignancies has been slower to develop. Reasons for this are multifaceted, including lack of specific antigens and antibodies optimized for RIT, difficulties in stably linking radionuclides to existing mAbs, shortfalls in existing (and readily available) radionuclides, and difficulty in clinical use (coordination between different specialties) [24]. However, clinical trials utilizing RIT in solid-tumor malignancies have been increasing.

The most common radionuclides employed have been ${ }^{90} \mathrm{Y}$ and ${ }^{131} \mathrm{I}$, with ${ }^{177} \mathrm{Lu}$ being used more recently. Based on the physical properties, each radionuclide may have an optimal tumor type and perform unique functions in clinical situations [25] (Table 1).

Prostate cancer is an ideal solid tumor malignancy for the utilization of RIT; the tumor is radiosensitive with high exposure to circulating antibodies (bone marrow and lymph nodes) through typical distribution. Although sometimes clinically problematic, early readouts of efficacy can be examined using serum prostate-specific antigen (PSA) levels. In preclinical and clinical PC settings, radionuclides have been linked to antibodies and/or peptides against mucin, ganglioside (L6), Lewis $\mathrm{Y}\left(\mathrm{Le}^{\mathrm{y}}\right)$, adenocarcinoma-associated antigens, and PSMA [26-36]. Of these, PSMA is the most specific and has been extensively studied in clinical trials.

Radioimmunotherapy can be delivered in a single dose or in multiple fractions. The degree of antitumor response following the administration of radiolabeled mAbs depends on several variables, specifically total (cumulative) radiation dose to the tumor, dose-rate, and tumor radiosensitivity. As with conventional external beam ionizing radiotherapy, dose fractionation may result in the ability to deliver a higher tumor dose with less toxicity. At the optimal dose-rate, fractionated dose RIT may decrease the amount of radiation to bone marrow while increasing the cumulative radiation dose to the tumor [37-39]. Preclinical data have shown that dose fractionation or multiple low-dose treatments can decrease toxicity while increasing the efficacy [40-42]. Early clinical studies have supported the ability to increase the cumulative maximum tolerated dose by dose fractionation [43-45].

Studies have shown that external beam RT can be combined with cytotoxic chemotherapy and, though toxicity may be increased, efficacy of concurrent chemoradiotherapy may be superior to sequential use. This may be especially true when utilizing chemotherapeutic agents with radiosensitizing effects. Combining RIT with cytotoxic chemotherapy has also been investigated $[30,31,46]$. These combinations have the possibility of increasing the therapeutic yield of RIT, particularly in the face of bulky, metastatic solid tumors.

With "targeted" therapy in general, patient selection can be significant. While our ability to preselect optimal PC patients based upon expression of a target has been limited, in other tumor types, reviewing targeted expression can be helpful in selecting patients more likely to respond or eliminating patients with a very low chance of response. For example, although epidermal growth factor receptor (EGFR) expression as measured by immunohistochemistry is not helpful in selecting patients for anti-EFGR mAb therapy in advanced colorectal carcinoma, excluding those with mutated K-ras has become helpful in clinical practice [47]. Specifically for PSMA expression, use of quantitative imaging, such as anti-PSMA-based positron emission tomography (PET) [48], may be more effective in selecting the best candidates (or ruling out poor candidates) for a PSMA-targeted therapeutic. When performing studies aimed to develop and examine predictive biomarkers, one must remember that prospective validation is important, as development of a "targeted" therapy may be thwarted by a suboptimal biomarker [49].

\section{Anti-Prostatic-Specific Membrane Antigen-Based Radioimmunotherapy}

Based on its apparent clinical ability to target some sites of disease, treatment studies were initiated utilizing radiolabeled capromab (CYT-356). In a phase I dose-escalation study, 12 patients with metastatic CRPC received ${ }^{90} \mathrm{Y}-\mathrm{CYT}$ 356 after biodistribution studies with ${ }^{111} \mathrm{In}-\mathrm{CTY}-356$ [26]. As expected with RIT, myelosuppression was the dose limiting toxicity (DLT). No objective responses (PSA or radiographic) 
TABLE 1: Radionuclide properties.

\begin{tabular}{llll}
\hline Radionuclide properties & ${ }^{131} \mathrm{I}$ & ${ }^{90} \mathrm{Y}$ & ${ }^{177} \mathrm{Lu}$ \\
\hline $\begin{array}{l}\text { Physical half-life (days) } \\
\text { Beta particles (mEv) }\end{array}$ & 8.05 & 2.67 & 6.7 \\
$\quad$ & & & 0.497 \\
$\quad$ max & 0.61 & 2.280 & 0.149 \\
$\quad$ average & 0.20 & 0.935 & 2.20 \\
$\quad$ & & 0.25 \\
$\quad$ mange in tissue (mm) & 2.4 & 12.0 & $0.113-0.208$ \\
$\quad$ average & 0.4 & 2.7 & $1-3 \mathrm{~mm}$ \\
Gamma emission (mEv) & 0.364 & None & \\
Optimal size of tumor when & $3-5 \mathrm{~mm}$ & $28-42 \mathrm{~mm}$ & Lacks gamma emissions (cannot use for \\
targeted for curability [25] & Cannot be used with internalizing & imaging) & \\
Comments & mAb's &
\end{tabular}

were noted. A subsequent phase II study utilizing ${ }^{90} \mathrm{Y}$-CYT356 was performed in men with biochemically recurrent prostate cancer [30], yet the study was stopped after significant toxicity (myelosuppression) and lack of efficacy (no PSA decline) were seen in the first 8 patients.

After determining that capromab was not capable of binding to viable PC cells, phase I clinical trials were performed linking Yttrium-90 $\left({ }^{90} \mathrm{Y}\right)$ or Lutetium-177 $\left({ }^{177} \mathrm{Lu}\right)$ to J591 via a DOTA chelate in patients with metastatic CRPC [25, 37]. Each of these studies was designed to deliver a single-dose of radiolabeled J591 intravenously followed by planar gamma camera imaging \pm SPECT (in the case of ${ }^{90} \mathrm{Y}-\mathrm{J} 591$, imaging was performed after ${ }^{111} \mathrm{In}-\mathrm{J} 591$ administration). These trials defined the DLT and maximum tolerated dose (MTD) and further refined dosimetry, pharmacokinetics, and HAHA of the radiolabeled $\mathrm{mAb}$ conjugates and demonstrated preliminary evidence of antitumor activity. The vast majority of patients demonstrated good tumor targeting by radiolabeled J591. A representative planar gamma camera image of radiolabeled J591 is displayed in Figure 1. As expected, based on the physical properties as described above, the MTD of single-dose ${ }^{177} \mathrm{Lu}-\mathrm{J} 591$ was higher $\left(70 \mathrm{mCi} / \mathrm{m}^{2}\right)$ than that of ${ }^{90} \mathrm{Y}-\mathrm{J} 591\left(17.5 \mathrm{mCi} / \mathrm{m}^{2}\right)$ $[34,35]$.

A phase II study was subsequently performed with ${ }^{177} \mathrm{Lu}-$ J591, confirming safety, efficacy, and tumor-targeting ability [50]. In a dual-center study, men with progressive metastatic CRPC received a ${ }^{177} \mathrm{Lu}-J 591$ intravenously followed by gamma camera imaging one week later. The results are promising and majority of patients demonstrated accurate targeting of known sites of metastatic disease, and PSA declines. All subjects experienced reversible hematologic toxicity without significant hemorrhagic complications. No serious drug-related nonhematologic toxicity occurred in either cohort.

In aggregate, based on the phase I and phase II data, these trials provide support that radiolabeled J591 is well tolerated with reversible myelosuppression, accurately targets PC metastatic sites, has antitumor activity, and is nonimmunogenic. However, as previously discussed, there are limitations to RIT for solid tumors, and the physical properties of ${ }^{177} \mathrm{Lu}$ should be suboptimal in treating the population treated to date (men with progressive metastatic CRPC were treated, many of whom had bulky disease). Additional studies to improve the therapeutic profile are in progress.

Based upon the rationale above, a US Department of Defense sponsored study utilizing fractionated dose ${ }^{177} \mathrm{Lu}-$ J591 has recently been completed with initial results of the primary endpoint presented [51]. Men with progressive metastatic CRPC received 2 fractionated doses two weeks apart. Doses were escalated in cohorts of 3-6 subjects, with cohort 1 receiving $20 \mathrm{mCi} / \mathrm{m}^{2} \times 2$ and each successive cohort undergoing dose escalation by $5 \mathrm{mCi} / \mathrm{m}^{2}$ per dose $\left(10 \mathrm{mCi} / \mathrm{m}^{2}\right.$ cumulative dose increase per cohort). The primary endpoint was to determine DLT and the cumulative MTD of fractionated ${ }^{177} \mathrm{Lu}$-J591 RIT with pharmacokinetics and dosimetry, and the secondary endpoint was efficacy. Dose limiting toxicity was defined as severe thrombocytopenia (platelet count $<15$ or need for $>3$ platelet transfusions in 30 days), grade 4 neutropenia $>7$ days, febrile neutropenia, or grade $>2$ nonhematologic toxicity. Twenty-eight subjects received treatment with cumulative doses of up to $90 \mathrm{mCi} / \mathrm{m}^{2}$ (highest planned dose). The median age was 72 years with median baseline PSA of $49 \mathrm{ng} / \mathrm{mL}$; the majority of subjects had Eastern Cooperative Oncology Group (ECOG) performance status of 1 and had bone metastases. The study confirmed the hypothesis that fractionated dosing would allow higher cumulative doses of ${ }^{177} \mathrm{Lu}-\mathrm{J} 591$ be administered with less toxicity.

Following progression on primary hormonal therapy, chemotherapy can offer symptomatic improvement as well as incremental survival benefit $[52,53]$. However, responses are transient and all men eventually suffer from progression of disease as described above with single-agent anti-PSMA based RIT. The combination of taxane chemotherapy with RT has been used in several diseases because of the radiosensitizing effects of taxane-based chemotherapy [54-56]. In addition to favorable results from fractionated RIT and the radiosensitizing effects of taxane-based chemotherapy, it is hypothesized that the additional debulking by chemotherapy will overcome some of the limits imposed by the physical characteristics of ${ }^{177} \mathrm{Lu}$. Based upon this theory, a phase I 


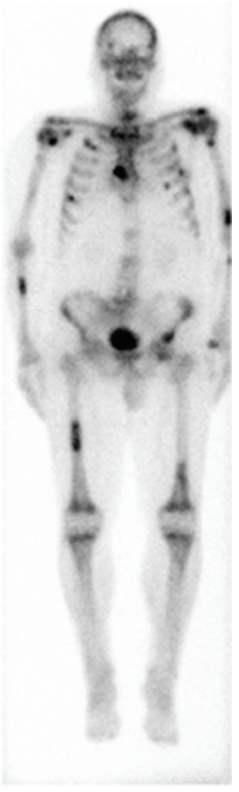

(a)

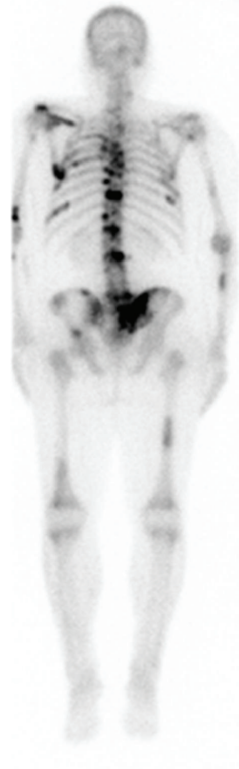

(b)

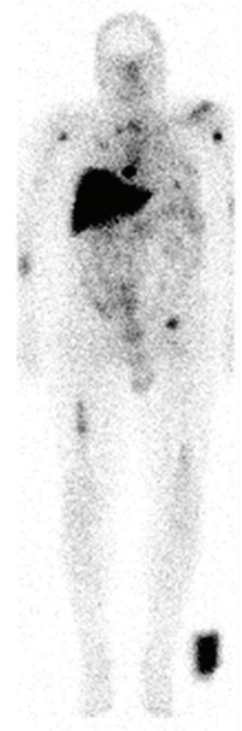

(c)

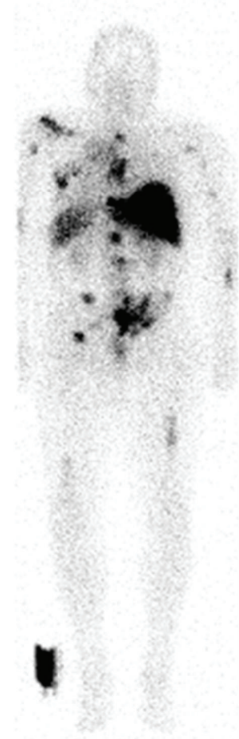

(d)

FIGURE 1: Radiolabeled J591 imaging. Left panels: Anterior (a) and posterior (b) images of pretreatment bony metastases on ${ }^{99 m}$ Tc-MDP bone scan. Right panels: Anterior (c) and posterior (d) total body images obtained via dual-head gamma camera of sites of uptake 7 days after ${ }^{177} \mathrm{Lu}-\mathrm{J} 591$ administration. (note, antibody is partly cleared via the liver resulting in nonspecific ${ }^{177} \mathrm{Lu}$ localization).

trial of docetaxel and prednisone with escalating doses of fractionated ${ }^{177} \mathrm{Lu}-J 591$ is ongoing [57].

As discussed above, the most studied form of RIT to date targets the $\mathrm{CD} 20$ antigen ( ${ }^{131}$ I tositumomab and ${ }^{90} \mathrm{Y}$ ibritumomab tiuxetan) in non-Hodgkin's lymphoma. While approved in the relapsed setting, it appears that these therapies have their greatest impact in the minimal disease setting [58-63]. The vast majority of relapses after local therapy for PC are initially "biochemical" only, that is, with a rising PSA despite no evidence of cancer on imaging, affecting approximately 50,000 men per year in the United States alone $[64,65]$. Although there is no proven overall survival benefit in a prospective randomized trial, radiotherapy as a salvage regimen can lead to longterm survival in selected individuals [66-69]. Unfortunately, most individuals subsequently suffer systemic progression because of subclinical micrometastatic disease outside of the radiation field.

Based on the demonstrated ability of J591-based therapy to successfully target known sites of disease and apparent clinical efficacy in the advanced setting, it is now under investigation in the salvage setting (clinicaltrials.gov NCT00859781). "Targeted radiotherapy" in the form of RIT is an attractive option with the possibility being a higher yield therapy in the minimal disease (biochemical only) setting. The primary objective of this trial is to prevent or delay radiographically evident metastatic disease. Radiolabeled J591 imaging will also be explored as a possible way to detect sites of disease in those patients with biochemical relapse and no evidence of disease on standard scans $\left({ }^{99 \mathrm{~m}} \mathrm{Tc}\right.$-MDP bone scans and computed tomography or magnetic resonance imaging) [70].

\section{Anti-Prostatic-Specific Membrane Antigen Antibody-Drug Conjugates}

Rather than linking a radionuclide to an $\mathrm{mAb}$, a drug or toxin can also be linked, forming an antibody-drug conjugate (ADC) [71]. In this form of therapy, drugs may be delivered to target cells, sparing normal cells from toxicity. Many advances have been made in ADC technology. Gemtuzumab ozogamicin is an anti-CD33 mAb conjugated to calicheamicin which was approved by the US FDA in 2000 for older patients with relapsed acute myeloid leukemia, though it has recently been withdrawn from the market. Many others are in late-stage development, including trastuzumabDM1 (anti-Her2 for breast cancer), inotuzumab, ozogamicin (anti-CD22 for non-Hodgkin's lymphoma), and brentuximab vedotin (anti-CD30 for Hodgkin's lymphoma).

MLN2704 is an ADC with maytansinoid 1 (DM1), which is a potent microtubule-depolymerizing compound conjugated to J591. Preclinical activity with MLN2704 was demonstrated [72] leading to a phase I trial designed to explore single ascending doses of the conjugate to define DLT, MTD, and PK [73]. Twenty-three subjects with metastatic CRPC received MLN2704 at doses ranging from $18-343 \mathrm{mg} / \mathrm{m}^{2}$ in an accelerated dose escalation scheme; 18 received at least 3 doses. Grade $\geq 3$ toxicities occurred in 2 subjects, including 1 episode of uncomplicated febrile neutropenia and transient grade 3 elevation of transaminases. One subject (treated at $343 \mathrm{mg} / \mathrm{m}^{2}$ ) achieved a $>50 \%$ decline in PSA, and another (treated at $264 \mathrm{mg} / \mathrm{m}^{2}$ ) experienced a PR by RECIST along with a $>50 \%$ decline in PSA.

A subsequent multicenter phase I/II study was initiated based on the above results [71]. Sixty-two subjects received 
multiple doses of MLN2704. Four regimens were tested, with PSA declines most frequent at $330 \mathrm{mg} / \mathrm{m}^{2}$ every 2 weeks ( $2 / 6$ had PSA decrease $>50 \%, 2 / 6$ had PSA stabilization). Although response was modest, and treatment was limited by toxicity, utilizing a PSMA mAb may be delivered in the clinic, and work is in progress and work is in progress utilizing new linkers to J591 designed to improve selective targeting.

Based on the PSMA selective expression in PC and the principle above, additional researchers have initiated further clinical work with toxin-conjugates that target PSMA. In the preclinical setting, A5-PE40 and D7-PE40 are recombinant anti-PSMA immunotoxins tested in vivo. Huang et al. inhibited the tumor growth in mice bearing subcutaneous LNCaP tumors with an immunotoxin consisting of the antiPSMA mAb E6 and deglycosylated ricin A [74]. Russell et al. coupled the melittin-like peptide 101 to anti-PSMA mAb J591 and obtained a significant tumor growth inhibition in mice [75]. Henry et al. used MLN2704 for the treatment of CWR22 xenografts [76]. Elsässer-Beile et al. reviewed other targeted systems against PSMA including RNA-aptamerbased immunotoxins [77]. Preclinical activity has been demonstrated in another mAb conjugated to monomethylauristatin E (MMAE) that recognizes the external domain of PSMA [78]. This work has led to a phase I dose-escalation study that has shown to be tolerated at the initial dose levels [79]. Additional early-stage clinical work has involved utilizing enzymatic activation to release cytotoxic substances in PSMA positive cells [80].

\section{Anti-Prostatic-Specific Membrane Antigen Immunotherapy}

Immunotherapy has been utilized in oncology over many decades, but only relatively recently has an autologous cellular immunotherapy agent (sipuleucel-T) been approved for clinical use in prostate cancer [81]. Though many attempts at utilizing immunotherapy in PC have focused on PSA $[82,83]$, as discussed, PSMA is an attractive target based on its restricted sites of expression. Multiple vaccine approaches have been utilized in preclinical models and have moved to early-stage clinical trials [83-88].

In addition to the deimmunization process in the transition from murine to human antibody, mAb J591 was engineered to interact with human immune effector cells and trigger antibody-dependent cell-mediated cytotoxicity (ADCC). In some of the initial studies with "cold" or "naked" J591 (unconjugated J591 with or without small doses of trace-labeled ${ }^{111}$ In-J591 for imaging purposes), stabilization of previously rising PSA occurred [89, 90]. Evidence of a dose-response relationship between $\mathrm{mAb}$ mass delivered and induction of ADCC was observed in a dose-escalation study enrolling patients with progressive CRPC [91]. One patient who received $100 \mathrm{mg}$ of $\mathrm{J} 591$ had a $>50 \%$ reduction in PSA.

Interleukin 2 (IL-2) promotes the proliferation and enhances the secretory capacity of all major types of lymphocytes, including T, B, and NK cells [92]. In addition, through its effects on NK cells, IL-2 stimulates antigennonspecific host reactions that involve interplay between
NK cells and monocytes. Based on these functions, IL-2 may be useful as an immune stimulant, particularly in the setting of cancer immunotherapy [93]. Within two weeks of low-dose IL-2 treatment, selective expansion of human $\mathrm{CD}^{-}, \mathrm{CD}^{-} 6^{+} \mathrm{NK}$ cells was seen with a plateau after 4 to 6 weeks of therapy $[94,95]$. Based on the hypothesis that J591 plus IL-2 would work together to effect a positive immune response against prostate cancer, a combination study was initiated [96]. Seventeen patients with recurrent prostate cancer received continuous low-dose subcutaneous IL-2 $\left(1.2 \times 10^{6} \mathrm{IU} / \mathrm{m}^{2} /\right.$ day $)$ daily for 8 weeks with weekly intravenous infusions of J591 $\left(25 \mathrm{mg} / \mathrm{m}^{2}\right)$ during weeks $4-$ 6. Therapy was well tolerated with a trend for those with significant NK cell expansion to be nonprogressors.

\section{Conclusion}

In summary, PSMA is the most highly specific PC cell-surface protein known. Prostate cancer represents an ideal disease for mAb-directed therapy, with PSMA as an optimal target. Current strategies aim to improve upon past successes in utilizing anti-PSMA mAbs to deliver toxic payloads specifically to PC cells, minimizing damage to normal organs. Clinical use to date include developments with anti-PSMA RIT and ADC. Additional work in early stages of development includes antiPSMA vaccines and utilizing PSMA-targeted therapy with or without other immune modulators to stimulate anti-PSMA ADCC.

\section{Funding}

Prostate Cancer Foundation, National Institutes of Health (ULI RR024996, 1-KL2-RR024997-01, PTBF5405), and Department of Defense supported this paper.

\section{Disclosure}

S. T. Tagawa is a member of the speakers bureau of Sanofi Aventis and accepted honoraria for lectures on docetaxel for prostate cancer within the past 3 years.

\section{References}

[1] J. S. Horoszewicz, E. Kawinski, and G. P. Murphy, "Monoclonal antibodies to a new antigenic marker in epithelial prostatic cells and serum of prostatic cancer patients," Anticancer Research, vol. 7, no. 5, pp. 927-935, 1987.

[2] R. S. Israeli, C. T. Powell, W. R. Fair, and W. D. W. Heston, "Molecular cloning of a complementary DNA encoding a prostate-specific membrane antigen," Cancer Research, vol. 53, no. 2, pp. 227-230, 1993.

[3] R. S. Israeli, C. T. Powell, J. G. Corr, W. R. Fair, and W. D. W. Heston, "Expression of the prostate-specific membrane antigen," Cancer Research, vol. 54, no. 7, pp. 1807-1811, 1994.

[4] G. L. Wright, C. Haley, M. L. Beckett, and P. F. Schellhammer, "Expression of prostate-specific membrane antigen in normal, benign, and malignant prostate tissues," Urologic Oncology, vol. 1, no. 1, pp. 18-28, 1995.

[5] J. K. Troyer, M. L. Beckett, and G. L. Wright Jr., "Detection and characterization of the prostate-specific membrane antigen 
(PSMA) in tissue extracts and body fluids," International Journal of Cancer, vol. 62, no. 5, pp. 552-558, 1995.

[6] R. Sokoloff, K. C. Norton, C. L. Gasior, K. M. Marker, and L. S. Grauer, "A dual-monoclonal sandwich assay for prostatespecific membrane antigen: levels in tissues, seminal fluid and urine," Prostate, vol. 43, no. 2, pp. 150-157, 2000.

[7] D. G. Bostwick, A. Pacelli, M. Blute, P. Roche, and G. P. Murphy, "Prostate specific membrane antigen expression in prostatic intraepithelial neoplasia and adenocarcinoma: a study of 184 cases," Cancer, vol. 82, no. 11, pp. 2256-2261, 1998.

[8] T. Kusumi, T. Koie, M. Tanaka et al., "Immunohistochemical detection of carcinoma in radical prostatectomy specimens following hormone therapy," Pathology International, vol. 58, no. 11, pp. 687-694, 2008.

[9] S. Mannweiler, P. Amersdorfer, S. Trajanoski, J. A. Terrett, D. King, and G. Mehes, "Heterogeneity of prostate-specific membrane antigen (PSMA) expression in prostate carcinoma with distant metastasis," Pathology and Oncology Research, vol. 15, no. 2, pp. 167-172, 2009.

[10] H. J. K. Ananias, M. C. van den Heuvel, W. Helfrich, and I. J. De Jong, "Expression of the gastrin-releasing peptide receptor, the prostate stem cell antigen and the prostate-specific membrane antigen in lymph node and bone metastases of prostate cancer," Prostate, vol. 69, no. 10, pp. 1101-1108, 2009.

[11] G. L. Wright Jr., B. M. Grob, C. Haley et al., "Upregulation of prostate-specific membrane antigen after androgen- deprivation therapy," Urology, vol. 48, no. 2, pp. 326-334, 1996.

[12] S. D. Sweat, A. Pacelli, G. P. Murphy, and D. G. Bostwick, "Prostate-specific membrane antigen expression is greatest in prostate adenocarcinoma and lymph node metastases," Urology, vol. 52, no. 4, pp. 637-640, 1998.

[13] S. S. Chang, V. E. Reuter, W. D. W. Heston, N. H. Bander, L. S. Grauer, and P. B. Gaudin, "Five different anti-prostate-specific membrane antigen (PSMA) antibodies confirm PSMA expression in tumor-associated neovasculature," Cancer Research, vol. 59, no. 13, pp. 3192-3198, 1999.

[14] J. T. Pinto, B. P. Suffoletto, T. M. Berzin et al., "Prostatespecific membrane antigen: a novel folate hydrolase in human prostatic carcinoma cells," Clinical Cancer Research, vol. 2, no. 9, pp. 1445-1451, 1996.

[15] D. Kahn, R. D. Williams, M. K. Haseman, N. L. Reed, S. J. Miller, and J. Gerstbrein, "Radioimmunoscintigraphy with In-111-labeled capromab pendetide predicts prostate cancer response to salvage radiotherapy after failed radical prostatectomy," Journal of Clinical Oncology, vol. 16, no. 1, pp. 284-289, 1998.

[16] D. Kahn, R. D. Williams, M. J. Manyak et al., "111Indiumcapromab pendetide in the evaluation of patients with residual or recurrent prostate cancer after radical prostatectomy," Journal of Urology, vol. 159, no. 6, pp. 2041-2047, 1998.

[17] M. J. Manyak, "Indium-111 capromab pendetide in the management of recurrent prostate cancer," Expert Review of Anticancer Therapy, vol. 8, no. 2, pp. 175-181, 2008.

[18] K. Bouchelouche, S. T. Tagawa, S. J. Goldsmith, B. Turkbey, J. Capala, and P. Choyke, "PET/CT imaging and radioimmunotherapy of prostate cancer," Seminars in Nuclear Medicine, vol. 41, no. 1, pp. 29-44, 2011.

[19] J. K. Troyer, M. L. Beckett, and G. L. Wright Jr., "Location of prostate-specific membrane antigen in the LNCaP prostate carcinoma cell line," Prostate, vol. 30, no. 4, pp. 232-242, 1997.

[20] H. Liu, P. Moy, S. Kim et al., "Monoclonal antibodies to the extracellular domain of prostate-specific membrane antigen also react with tumor vascular endothelium," Cancer Research, vol. 57, no. 17, pp. 3629-3634, 1997.
[21] H. Liu, A. K. Rajasekaran, P. Moy et al., "Constitutive and antibody-induced internalization of prostate-specific membrane antigen," Cancer Research, vol. 58, no. 18, pp. 40554060, 1998.

[22] D. Yao, E. J. Trabulsi, L. Kostakoglu et al., "The utility of monoclonal antibodies in the imaging of prostate cancer," Seminars in Urologic Oncology, vol. 20, no. 3, pp. 211-218, 2002.

[23] N. H. Bander, D. M. Nanus, M. I. Milowsky, L. Kostakoglu, S. Vallabahajosula, and S. J. Goldsmith, "Targeted systemic therapy of prostate cancer With a monoclonal antibody to prostate-specific membrane antigen," Seminars in Oncology, vol. 30, no. 5, pp. 667-677, 2003.

[24] C. Divgi, "What ails solid tumor radioimmunotherapy?" Cancer Biotherapy and Radiopharmaceuticals, vol. 21, no. 2, pp. 81-84, 2006.

[25] J. A. O'Donoghue, M. Bardies, T. E. Wheldon, and G. Sgouros, "Relationships between tumor size and curability for uniformly targeted therapy with beta-emitting radionuclides," Journal of Nuclear Medicine, vol. 36, no. 10, pp. 1902-1912, 1995.

[26] N. Deb, M. Goris, K. Trisler et al., "Treatment of hormonerefractory prostate cancer with Y-CYT-356 monoclonal antibody," Clinical Cancer Research, vol. 2, no. 8, pp. 1289-1297, 1996.

[27] D. Kahn, J. C. Austin, R. T. Maguire, S. J. Miller, J. Gerstbrein, and R. D. Williams, "A phase II study of [90Y]yttriumcapromab pendetide in the treatment of men with prostate cancer recurrence following radical prostatectomy," Cancer Biotherapy and Radiopharmaceuticals, vol. 14, no. 2, pp. 99111, 1999.

[28] R. F. Meredith, A. J. Bueschen, M. B. Khazaeli et al., "Treatment of metastatic prostate carcinoma with radiolabeled antibody CC49," Journal of Nuclear Medicine, vol. 35, no. 6, pp. 1017-1022, 1994.

[29] R. T. O'Donnell, S. J. DeNardo, A. Yuan et al., "Radioimmunotherapy with In/Y-2IT-BAD-m170 for metastatic prostate cancer," Clinical Cancer Research, vol. 7, no. 6, pp. 1561-1568, 2001.

[30] R. T. O’Donnell, S. J. Denardo, L. A. Miers et al., "Combined modality radioimmunotherapy for human prostate cancer xenografts with taxanes and Yttrium-DOTA-peptide-ChL6," Prostate, vol. 50, no. 1, pp. 27-37, 2002.

[31] C. M. Richman, S. J. DeNardo, R. T. O’Donnell et al., "High-dose radioimmunotherapy combined with fixed, lowdose paclitaxel in metastatic prostate and breast cancer by using a MUC-1 monoclonal antibody, m170, linked to indium-111/yttrium-90 via a cathepsin cleavable linker with cyclosporine to prevent human anti-mouse antibody," Clinical Cancer Research, vol. 11, no. 16, pp. 5920-5927, 2005.

[32] M. P. Kelly, F. T. Lee, K. Tahtis, F. E. Smyth, M. W. Brechbiel, and A. M. Scott, "Radioimmunotherapy with $\alpha$ particle-emitting 213Bi-C- functionalized trans-cyclohexyldiethylenetriaminepentaacetic acid-humanized $3 S 193$ is enhanced by combination with paclitaxel chemotherapy," Clinical Cancer Research, vol. 13, no. 18, pp. 5604s-5612s, 2007.

[33] D. W. Schneider, T. Heitner, B. Alieke et al., "In vivo bodistribution, PET imaging, and tumor accumulation of $86 \mathrm{Y}-$ and 111 In-antimindin/RG-1, engineered antibody fragments in LNCaP tumor-bearing nude mice," Journal of Nuclear Medicine, vol. 50, no. 3, pp. 435-443, 2009.

[34] M. I. Milowsky, D. M. Nanus, L. Kostakoglu, S. Vallabhajosula, S. J. Goldsmith, and N. H. Bander, "Phase I trial of yttrium-90labeled anti-prostate-specific membrane antigen monoclonal 
antibody J591 for androgen-independent prostate cancer," Journal of Clinical Oncology, vol. 22, no. 13, pp. 2522-2531, 2004.

[35] N. H. Bander, M. I. Milowsky, D. M. Nanus, L. Kostakoglu, S. Vallabhajosula, and S. J. Goldsmith, "Phase I trial of ${ }^{177}$ Lutetium-labeled J591, a monoclonal antibody to prostatespecific membrane antigen, in patients with androgenindependent prostate cancer," Journal of Clinical Oncology, vol. 23, no. 21, pp. 4591-4601, 2005.

[36] S. T. Tagawa, H. Beltran, S. Vallabhajosula et al., "Antiprostate-specific membrane antigen-based radioimmunotherapy for prostate cancer," Cancer, vol. 116, no. 4, supplement, pp. 1075-1083, 2010.

[37] G. L. DeNardo, J. Schlom, D. J. Buchsbaum et al., "Rationales, evidence, and design considerations for fractionated radioimmunotherapy," Cancer, vol. 94, no. 4, supplement, pp. 1332 $1348,2002$.

[38] J. A. O’Donoghue, G. Sgouros, C. R. Divgi, and J. L. Humm, "Single-dose versus fractionated radioimmunotherapy: model comparisons for uniform tumor dosimetry," Journal of Nuclear Medicine, vol. 41, no. 3, pp. 538-547, 2000.

[39] S. Shen, J. Duan, R. F. Meredith et al., "Model prediction of treatment planning for dose-fractionated radioimmunotherapy," Cancer, vol. 94, no. 4, supplement, pp. 1264-1269, 2002.

[40] L. A. Kroger, G. L. DeNardo, P. H. Gumerlock et al., "Apoptosis-related gene and protein expression in human lymphoma xenografts (Raji) after low dose rate radiation using 67Cu-2IT-BAT-Lym-1 radioimmunotherapy," Cancer Biotherapy and Radiopharmaceuticals, vol. 16, no. 3, pp. 213225, 2001.

[41] H. M. Vriesendorp, Y. Shao, J. E. Blum, S. M. Quadri, and J. R. Williams, "Fractionated intravenous administration of Ylabeled B72.3 GYK-DTPA immunoconjugate in beagle dogs," Nuclear Medicine and Biology, vol. 20, no. 5, pp. 571-578, 1993.

[42] D. Buchsbaum, M. B. Khazaeli, T. Liu et al., "Fractionated radioimmumotherapy of human colon carcinoma xenografts with ${ }^{131}$ I-labeled monoclonal antibody CC49," Cancer Research, vol. 55, no. 23, supplement, pp. 5881S-5887S, 1995.

[43] G. L. DeNardo, S. J. DeNardo, K. R. Lamborn et al., "Lowdose, fractionated radioimmunotherapy for B-cell malignancies using 131I-LYM-1 antibody," Cancer Biotherapy and Radiopharmaceuticals, vol. 13, no. 4, pp. 239-254, 1998.

[44] M. G. Steffens, O. C. Boerman, W. J. G. Oyen et al., "Intratumoral distribution of two consecutive injections of chimeric antibody G250 in primary renal cell carcinoma: implications for fractionated dose radioimmunotherapy," Cancer Research, vol. 59, no. 7, pp. 1615-1619, 1999.

[45] C. Hindorf, O. Lindén, L. Stenberg, J. Tennvall, and S. E. Strand, "Change in tumor-absorbed dose due to decrease in mass during fractionated radioimmunotherapy in lymphoma patients," Clinical Cancer Research, vol. 9, no. 10, pp. 4003S4006S, 2003.

[46] M. P. Kelly, F. T. Lee, F. E. Smyth, M. W. Brechbiel, and A. M. Scott, "Enhanced efficacy of Y-radiolabeled anti-lewis Y humanized monoclonal antibody hu3S193 and paclitaxel combined-modality radioimmunotherapy in a breast cancer model," Journal of Nuclear Medicine, vol. 47, no. 4, pp. 716725,2006

[47] C. J. Allegra, J. M. Jessup, M. R. Somerfield et al., "American society of clinical oncology provisional clinical opinion: testing for KRAS gene mutations in patients with metastatic colorectal carcinoma to predict response to anti-epidermal growth factor receptor monoclonal antibody therapy," Journal of Clinical Oncology, vol. 27, no. 12, pp. 2091-2096, 2009.

[48] J. P. Holland, V. Divilov, N. H. Bander, P. M. Smith-Jones, S. Larson, and J. S. Lewis, " ${ }^{89} \mathrm{Zr}$-DFO-J591 for immunoPET of prostate-specific membrane antigen expression in vivo," Journal of Nuclear Medicine, vol. 51, no. 8, pp. 1293-1300, 2010.

[49] S. N. Khleif, J. H. Doroshow, and W. N. Hait, "AACRFDA-NCI cancer biomarkers collaborative consensus report: advancing the use of biomarkers in cancer drug development," Clinical Cancer Research, vol. 16, no. 13, pp. 3299-3318, 2010.

[50] S. T. Tagawa, M. I. Milowsky, M. Morris et al., "Phase II trial of ${ }^{177}$ Lutetium radiolabeled anti-prostate-specific membrane antigen (PSMA) monoclonal antibody J591 (177Lu-J591) in patients (pts) with metastatic castrate-resistant prostate cancer (metCRPC)," Journal of Clinical Oncology, vol. 26, no. 15, supplement, p. 284s, 2008, abstract no. 5140.

[51] S.T. Tagawa, S. Vallabhajosula, J. Osborne et al., "Phase I trial of fractionated-dose ${ }^{177}$ lutetium radiolabeled anti-prostatespecific membrane antigen (PSMA) monoclonal antibody J591 $\left({ }^{177} \mathrm{Lu}-\mathrm{J} 591\right)$ in patients (pts) with metastatic castrationresistant prostate cancer (metCRPC)," Journal of Clinical Oncology, vol. 28, no. 15, supplement, 2010, abstract no. 4667.

[52] D. P. Petrylak, C. M. Tangen, M. H. A. Hussain et al., "Docetaxel and estramustine compared with mitoxantrone and prednisone for advanced refractory prostate cancer," The New England Journal of Medicine, vol. 351, no. 15, pp. 15131520, 2004.

[53] I. F. Tannock, R. de Wit, W. R. Berry et al., "Docetaxel plus prednisone or mitoxantrone plus prednisone for advanced prostate cancer," The New England Journal of Medicine, vol. 351, no. 15, pp. 1502-1512, 2004.

[54] H. Choy, F. F. Rodriguez, S. Koester, S. Hilsenbeck, and D. D. Von Hoff, "Investigation of taxol as a potential radiation sensitizer," Cancer, vol. 71, no. 11, pp. 3774-3778, 1993.

[55] R. B. Tishler, P. B. Schiff, C. R. Geard, and E. J. Hall, "Taxol: a novel radiation sensitizer," International Journal of Radiation Oncology Biology Physics, vol. 22, no. 3, pp. 613-617, 1992.

[56] C. Hennequin, N. Giocanti, and V. Favaudon, "Interaction of ionizing radiation with paclitaxel (taxol) and docetaxel (taxotere) in HeLa and SQ20B cells," Cancer Research, vol. 56, no. 8, pp. 1842-1850, 1996.

[57] H. Beltran, S. Vallabhajosula, W. K. Kelly et al., "Phase I dose escalation study of Docetaxel/Predisone and fractionated ${ }^{177} \mathrm{Lu}$-J591 for metastatic castrate resistant prostate cancer (metCRPC)," Journal of Clinical Oncology, vol. 28, no. 15, supplement, 2010, abstract no. TPS247.

[58] M. S. Kaminski, J. Estes, K. R. Zasadny et al., "Radioimmunotherapy with iodine 131I tositumomab for relapsed or refractory B-cell non-Hodgkin lymphoma: updated results and long-term follow-up of the University of Michigan experience," Blood, vol. 96, no. 4, pp. 1259-1266, 2000.

[59] M. S. Kaminski, A. D. Zelenetz, O. W. Press et al., "Pivotal study of iodine I 131 tositumomab for chemotherapyrefractory low-grade or transformed low-grade B-cell nonHodgkin's lymphomas," Journal of Clinical Oncology, vol. 19, no. 19, pp. 3918-3928, 2001.

[60] O. W. Press, J. M. Unger, R. M. Braziel et al., "A phase 2 trial of CHOP chemotherapy followed by tositumomab/iodine I 131 tositumomab for previously untreated follicular nonHodgkin lymphoma: southwest Oncology Group Protocol S9911," Blood, vol. 102, no. 5, pp. 1606-1612, 2003.

[61] M. S. Kaminski, M. Tuck, J. Estes et al., "I-tositumomab therapy as initial treatment for follicular lymphoma," The New England Journal of Medicine, vol. 352, no. 5, pp. 441-449, 2005. 
[62] J. P. Leonard, M. Coleman, L. Kostakoglu et al., "Abbreviated chemotherapy with fludarabine followed by tositumomab and iodine I 131 tositumomab for untreated follicular lymphoma," Journal of Clinical Oncology, vol. 23, no. 24, pp. 5696-5704, 2005.

[63] O. W. Press, J. M. Unger, R. M. Braziel et al., "Phase II trial of CHOP chemotherapy followed by tositumomab/iodine I-131 tositumomab for previously untreated follicular nonHodgkin's lymphoma: five-year follow-up of Southwest Oncology Group protocol S9911," Journal of Clinical Oncology, vol. 24, no. 25, pp. 4143-4149, 2006.

[64] J. W. Moul, "Prostate specific antigen only progression of prostate cancer," Journal of Urology, vol. 163, no. 6, pp. 1632$1642,2000$.

[65] H. I. Scher, M. Eisenberger, A. V. D’Amico et al., "Eligibility and outcomes reporting guidelines for clinical trials for patients in the state of a rising prostate-specific antigen: recommendations from the Prostate-Specific Antigen Working Group," Journal of Clinical Oncology, vol. 22, no. 3, pp. 537556, 2004.

[66] J. F. Pazona, M. Han, S. A. Hawkins, K. A. Roehl, and W. J. Catalona, "Salvage radiation therapy for prostate specific antigen progression following radical prostatectomy: 10-Year outcome estimates," Journal of Urology, vol. 174, no. 4, pp. 1282-1286, 2005.

[67] S. J. Buskirk, T. M. Pisansky, S. E. Schild et al., "Salvage radiotherapy for isolated prostate specific antigen increase after radical prostatectomy: evaluation of prognostic factors and creation of a prognostic scoring system," Journal of Urology, vol. 176, no. 3, pp. 985-990, 2006.

[68] A. J. Stephenson, S. F. Shariat, M. J. Zelefsky et al., "Salvage radiotherapy for recurrent prostate cancer after radical prostatectomy," Journal of the American Medical Association, vol. 291, no. 11, pp. 1325-1332, 2004.

[69] J. F. Ward, H. Zincke, E. J. Bergstralh, J. M. Slezak, and M. L. Blute, "Prostate specific antigen doubling time subsequent to radical prostatectomy as a prognosticator of outcome following salvage radiotherapy," Journal of Urology, vol. 172, no. 6, pp. 2244-2248, 2004.

[70] S. T. Tagawa, J. Osborne, P. J. Christos et al., "A randomized phase II trial of ${ }^{177} \mathrm{lu}$ radiolabeled monoclonal antibody J591 ( $\left.{ }^{177} \mathrm{Lu}-J 591\right)$ and ketoconazole in patients (pts) with high-risk castrate biochemically relapsed prostate cancer after local therapy," Journal of Clinical Oncology, vol. 28, no. 15, supplement, 2010, abstract no. TPS248.

[71] S. C. Alley, N. M. Okeley, and P. D. Senter, "Antibody-drug conjugates: targeted drug delivery for cancer," Current Opinion in Chemical Biology, vol. 14, no. 4, pp. 529-537, 2010.

[72] M. D. Henry, S. Wen, M. D. Silva, S. Chandra, M. Milton, and P. J. Worland, "A prostate-specific membrane antigen-targeted monoclonal antibody-chemotherapeutic conjugate designed for the treatment of prostate cancer," Cancer Research, vol. 64, no. 21, pp. 7995-8001, 2004.

[73] M. Galsky, M. Eisenberger, S. Moore-Cooper et al., "First in man study of the prostate specific membrane antigen targeted immunoconjugate, MLN2704, in patients with progressive castrate metastatic prostate cancer (PCMPC): updated results," in Proceedings of the Prostate Cancer Symposium, Orlando, Fla, USA, 2005.

[74] X. Huang, M. Bennett, and P. E. Thorpe, "Anti-tumor effects and lack of side effects in mice of an immunotoxin directed against human and mouse prostate-specific membrane antigen," Prostate, vol. 61, no. 1, pp. 1-11, 2004.

[75] P. J. Russell, D. Hewish, T. Carter et al., "Cytotoxic properties of immunoconjugates containing melittin-like peptide 101 against prostate cancer: In vitro and in vivo studies," Cancer Immunology, Immunotherapy, vol. 53, no. 5, pp. 411-421, 2004.

[76] M. D. Henry, S. Wen, M. D. Silva, S. Chandra, M. Milton, and P. J. Worland, "A prostate-specific membrane antigen-targeted monoclonal antibody-chemotherapeutic conjugate designed for the treatment of prostate cancer," Cancer Research, vol. 64, no. 21, pp. 7995-8001, 2004.

[77] U. Elsässer-Beile, P. Bühler, and P. Wolf, "Targeted therapies for Prostate cancer against the prostate specific membrane antigen," Current Drug Targets, vol. 10, no. 2, pp. 118-125, 2009.

[78] D. Ma, C. E. Hopf, A. D. Malewicz et al., "Potent antitumor activity of an auristatin-conjugated, fully human monoclonal antibody to prostate-specific membrane antigen," Clinical Cancer Research, vol. 12, no. 8, pp. 2591-2596, 2006.

[79] D. P. Petrylak, P. W. Kantoff, Y. Rotshteyn et al., "Prostatespecific membrane antigen antibody drug conjugate (PSMA ADC): a phase I trial in taxane-refractory prostate cancer," Journal of Clinical Oncology, vol. 29, supplement 7, 2011, abstract no. 158.

[80] S. R. Denmeade, "Prostate-specific membrane antigen activated prodrug and imaging agents," abstract no. P19-58.

[81] P. W. Kantoff, C. S. Higano, N. D. Shore et al., "Sipuleucel-T immunotherapy for castration-resistant prostate cancer," The New England Journal of Medicine, vol. 363, no. 5, pp. 411-422, 2010.

[82] C. G. Drake, "Prostate cancer as a model for tumour immunotherapy," Nature Reviews Immunology, vol. 10, no. 8, pp. 580-593, 2010.

[83] S. Alam and D. G. McNeel, "DNA vaccines for the treatment of prostate cancer," Expert Review of Vaccines, vol. 9, no. 7, pp. 731-745, 2010.

[84] S. F. Slovin, "Prostate-specific membrane antigen vaccines: naked DNA and protein approaches," Clinical Prostate Cancer, vol. 4, no. 2, pp. 118-123, 2005.

[85] R. J. Durso, S. Andjelic, J. P. Gardner et al., "A novel alphavirus vaccine encoding prostate-specific membrane antigen elicits potent cellular and humoral immune responses," Clinical Cancer Research, vol. 13, no. 13, pp. 3999-4008, 2007.

[86] M. Fishman, "A changing world for DCvax: a PSMA loaded autologous dendritic cell vaccine for prostate cancer," Expert Opinion on Biological Therapy, vol. 9, no. 12, pp. 1565-1575, 2009.

[87] Y. Kuang, H. Zhu, X. Weng et al., "Antitumor immune response induced by DNA vaccine encoding human prostatespecific membrane antigen and mouse 4-1BBL," Urology, vol. 76, no. 2, pp. 510.e1-510.e6, 2010.

[88] B. Ferraro, N. J. Cisper, K. T. Talbott et al., "Co-delivery of PSA and PSMA DNA vaccines with electroporation induces potent immune responses," Human Vaccines, vol. 7, pp. 120127, 2011.

[89] N. H. Bander, D. Nanus, S. Bremer et al., "Phase I clinical trial targeting a monoclonal antibody (mAb) to the extracellular domain of prostate specific membrane antigen (PSMAext) in patients with hormone-independent prostate cancer," American Society of Clinical Oncology, vol. 19, 2000, abstract no. 1872.

[90] N. H. Bander, D. Nanus, S. Goldstein et al., "Phase I trial of humanized monoclonal antibody $(\mathrm{mAb})$ to prostate specific membrane Antigen/Extracellular domain (PSMAext)," American Society of Clinical Oncology, vol. 20, 2001, abstract no. 722.

[91] M. J. Morris, C. R. Divgi, N. Pandit-Taskar et al., "Pilot trial of unlabeled and indium-111-labeled anti-prostate-specific 
membrane antigen antibody J591 for castrate metastatic prostate cancer," Clinical Cancer Research, vol. 11, no. 20, pp. 7454-7461, 2005.

[92] K. A. Smith, "Interleukin-2: inception, impact, and implications," Science, vol. 240, no. 4856, pp. 1169-1176, 1988.

[93] G. G. Hillman, J. A. Triest, M. L. Cher, S. V. Kocheril, and B. R. Talati, "Prospects of immunotherapy for the treatment of prostate carcinoma-a review," Cancer Detection and Prevention, vol. 23, no. 4, pp. 333-342, 1999.

[94] K. A. Smith, "Lowest dose interleukin-2 immunotherapy," Blood, vol. 81, no. 6, pp. 1414-1423, 1993.

[95] T. A. Fehniger, E. M. Bluman, M. M. Porter et al., "Potential mechanisms of human natural killer cell expansion in vivo during low-dose IL-2 therapy," Journal of Clinical Investigation, vol. 106, no. 1, pp. 117-124, 2000.

[96] S. J. Jeske, M. I. Milowsky, C. R. Smith, K. A. Smith, N. H. Bander, and D. M. Nanus, "Phase II trial of the anti-prostate specific membrane antigen (PSMA) monoclonal antibody (mAb) J591 plus low-dose interleukin-2 (IL-2) in patients (pts) with recurrent prostate cancer (PC)," Journal of Clinical Oncology, vol. 25, no. 18, supplement, 2007, ASCO Annual Meeting Proceedings Part I, abstract no. 15558. 


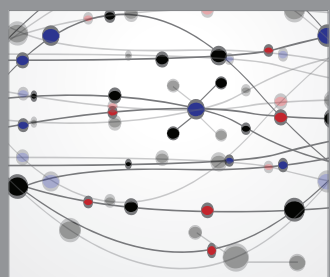

The Scientific World Journal
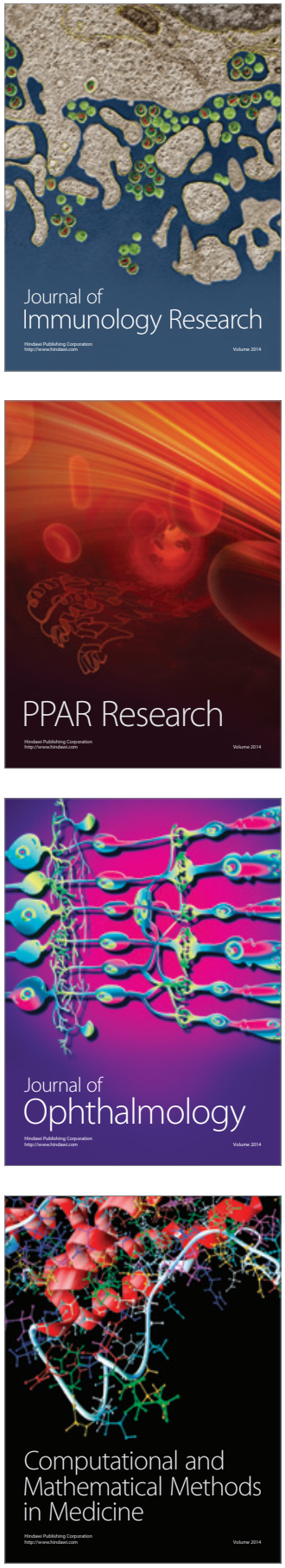

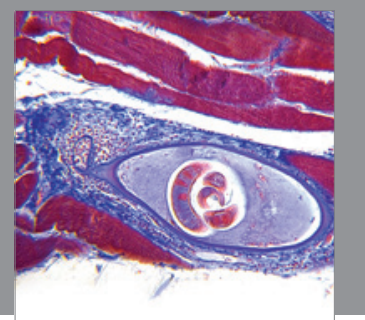

Gastroenterology

Research and Practice
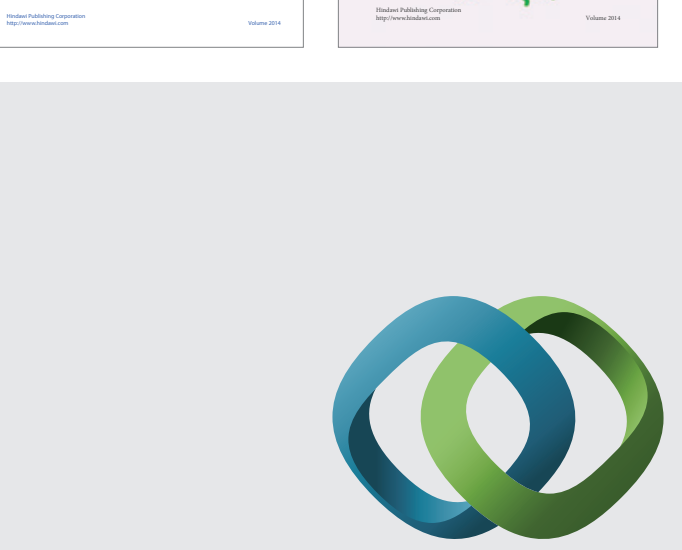

\section{Hindawi}

Submit your manuscripts at

http://www.hindawi.com
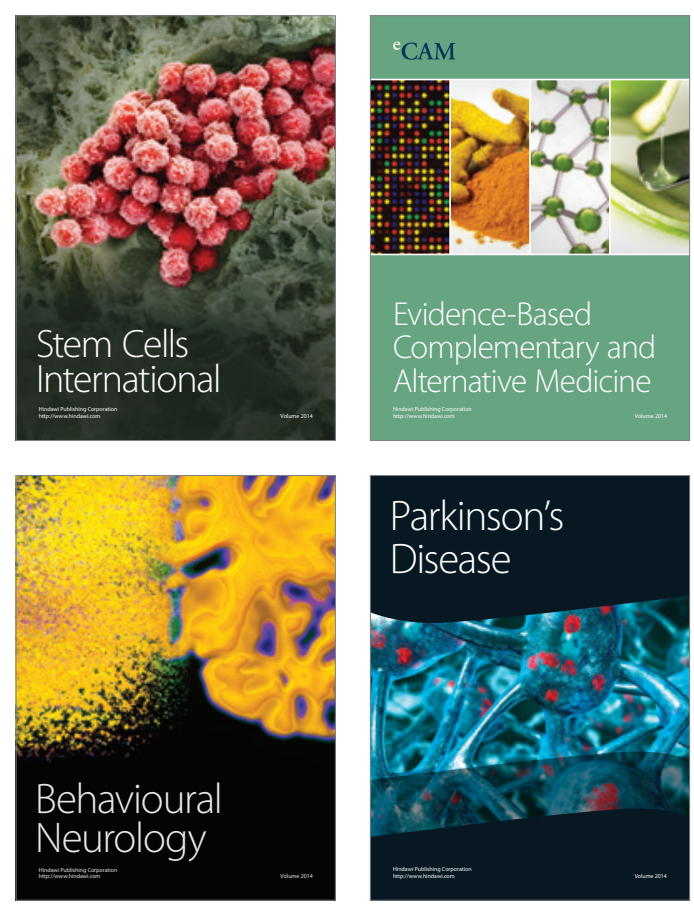

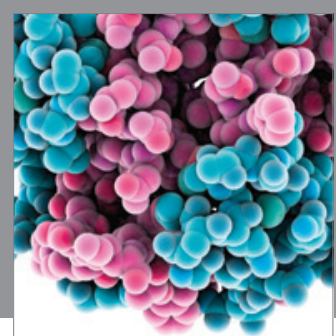

Journal of
Diabetes Research

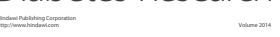

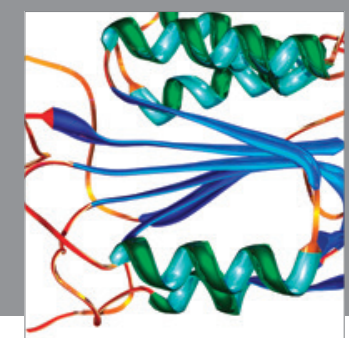

Disease Markers
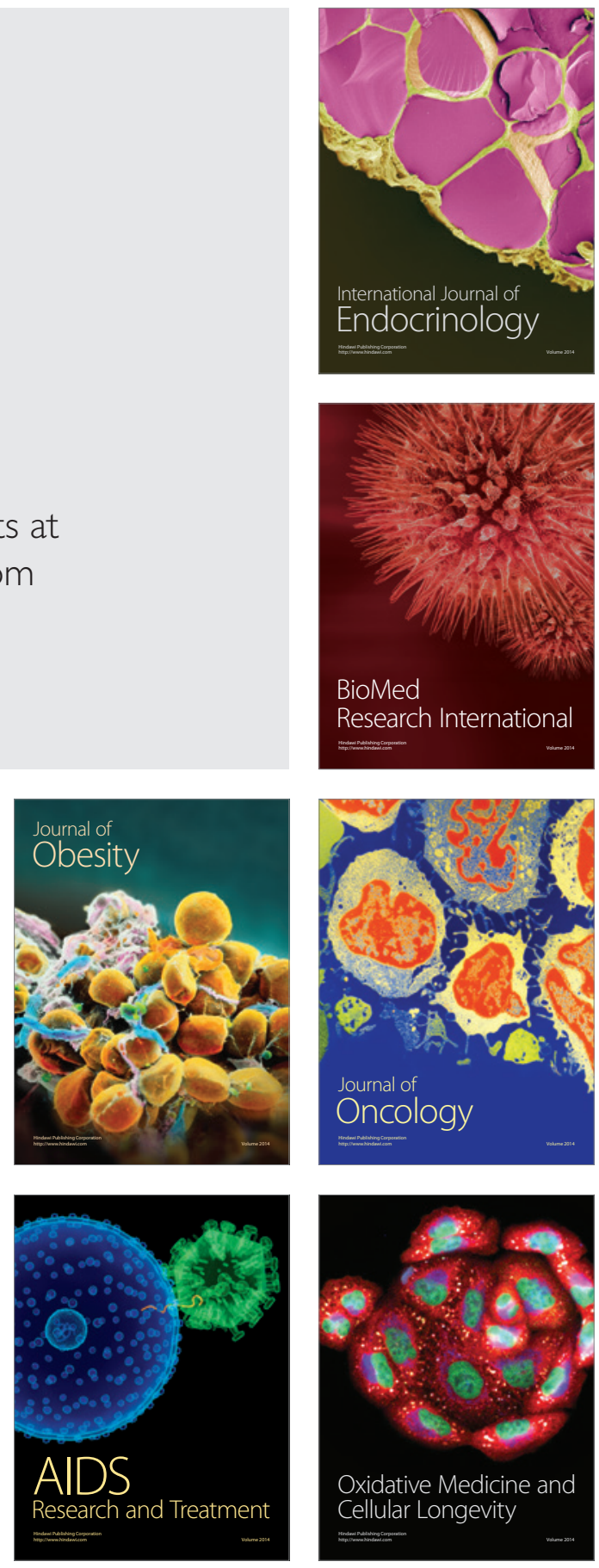